\title{
Food, physical activity and climate change perspectives in relationship to allotment ownership
}

\author{
A. M. Hunt ${ }^{1}$, C. Burek $^{1}$ and B. Ellahi ${ }^{1}$ \\ ${ }^{1}$ University of Chester, Parkgate Road, Chester, $\mathrm{CHI} 4 \mathrm{BJ}$
}

Obesity and climate change are two of the biggest public health crises that the world currently faces and will face for many years to come, unless action is taken to halt the causes. The link between diet, physical activity and obesity has been firmly established ${ }^{(1)}$. The causes of obesity are however, a multi-faceted problem, as are the causes of climate change. Current food production has been linked to increasing levels of $\mathrm{CO}_{2}$, and current eating habits can be responsible for a large carbon footprint ${ }^{(2)}$. Growing your own food has been suggested as a method of reducing one's carbon footprint, increasing physical activity levels and improving diet ${ }^{(3)}$, little evidence exists to support this theory. This study looks at the fruit and vegetable consumption, physical activity levels and climate change awareness of allotment holders in two wards of Stockport. The aim being to analyse the association between allotment 'ownership' and health status and incorporating climate change knowledge, to clarify the rationale for allotment use as a means of obesity reduction/ prevention.

Qualitative and quantitative data was collected via face to face questionnaires $(n=28)$ at both allotments sites.

Fruit and vegetable intakes of allotment holders were found to be above those of the U.K. general public and intake increased after allotment ownership (1.2 portions). The number of participants achieving 5-a-day increased with allotment ownership ( $n=2$ to $n=12$ ). Physical activity levels were on average, higher than the recommendation of thirty minutes a day for at least five days per week and generally increased after uptake of the allotment (mean increase 718 MET minutes). Allotment owners rent plots for a combination of reasons; the majority wanting to grow their own food, and get exercise and most also cite some form of environmental issue. All participants were aware of climate change and although not all thought it would affect allotments; most had ideas of what they would do to adapt to changes. There are synergies between solving climate change issues, such as Green House Gas emissions and improving our health, both physically and nutritionally.

Growing your own fruit and vegetables on an allotment can increase your consumption of fruit and vegetables significantly, increase your exercise levels and reduce your $\mathrm{CO}_{2}$ emissions, thus confirming the rationale of allotment use as a means of obesity reduction or prevention.

1. Foresight Government Office for Science (2007) Foresight Tackling Obesities: Future Choices 2nd Edition - Modelling Future Trends in Obesity \& Their Impact on Health.

2. Stern (2006) Stern review on economics of climate change, Cambridge University Press, London.

3. Stockport JNSA (2009) Tackling Obesity Life Course Mapping 09/10 (Draft-work in progress). 